\title{
ALTERIDADE E EDUCAÇÃO: UM DIÁLOGO INTERSUBJETIVO PELO VIÉS DA DIVERSIDADE
}

\author{
ALTERIDAD Y EDUCACIÓN: UN DIÁLOGO INTERSUBJETIVO POR BIAS DE LA \\ DIVERSIDAD
}

\author{
ALTERATION AND EDUCATION: AN INTERSUBJECTIVE DIALOGUE FOR THE \\ VIES OF DIVERSITY
}

\author{
Adilson Cristiano HABOWSKI ${ }^{1}$ \\ Elaine $\mathrm{CONTE}^{2}$ \\ Daniel Felipe JACOBI ${ }^{3}$
}

RESUMO: O presente ensaio, de alicerce hermenêutico, visa promover um diálogo com a diversidade sexual na educação, colocando como desafio a construção de uma cultura aberta às múltiplas linguagens e às diferenças, como forma de reduzir preconceitos, discriminações e aprender com a multiplicidade na escola. Alicerçados na filosofia de Emmanuel Lévinas, somos provocados a aprender com o outro, rumo à formação de uma inteligência coletiva que promova a vida e qualifique o saber social e diverso, indo além da repetição de identidades de gênero constituídas historicamente. A complexidade da tarefa implica reconhecer o outro por meio de ações que permitam sair do imobilismo preconceituoso, reconstruindo práticas pedagógicas que expressem a riqueza das identidades pelo diálogo cultural repensado com as possibilidades da diversidade e da pluralidade.

PALAVRAS-CHAVE: Alteridade. Educação. Diversidade sexual.

RESUMEN: El presente ensayo, de base hermenéutica, pretende promover un diálogo con la diversidad sexual en la educación, planteando como desafío la construcción de una cultura abierta a los múltiples lenguajes y las diferencias, como forma de reducir prejuicios, discriminaciones y aprender de la multiplicidad en la escuela. Alentados en la filosofía de Emmanuel Lévinas, estamos provocados a aprender con el otro, hacia la formación de una inteligencia colectiva que promueve la vida y califique el saber social y diverso, yendo más allá de la repetición de identidades de género constituidas históricamente. La complejidad de la tarea implica reconocer al otro por medio de acciones que permitan salir del inmovilismo preconcebido, reconstruyendo prácticas pedagógicas que expresen la riqueza de las identidades por el diálogo cultural repensado con las posibilidades de la diversidad y de la pluralidad.

PALABRAS CLAVE: Otredad. Educación. Diversidad sexual.

\footnotetext{
${ }^{1}$ Universidade La Salle - (Unilasalle), Canoas - RS - Brasil. Mestrando em Educação na Universidade La Salle. ORCID: <http://orcid.org/0000-0002-5378-7981>. E-mail: adilsonhabowski@ hotmail.com

${ }^{2}$ Universidade La Salle - (Unilasalle), Canoas - RS - Brasil. Professora do Programa de Pós-Graduação em Educação da Universidade La Salle. ORCID: 〈http://orcid.org/0000-0002-0204-0757>. E-mail: elaine.conte@unilasalle.edu.br

${ }^{3}$ Universidade La Salle - (Unilasalle), Canoas - RS - Brasil. E-mail: danielfjacobi@ hotmail.com
} 
ABSTRACT: This essay aims to promote a dialogue with sexual diversity in education, placing as challenge the construction of a culture open to multiple languages and differences, as a way to reduce prejudice, discrimination and learn with multiplicity in school. Based on the philosophy of Emmanuel Lévinas, we are provoked to learn from each other, towards the formation of a collective intelligence that promotes life and qualifies social and diverse knowledge, going beyond the repetition of historically constituted gender identities. The complexity of the task implies recognizing the other by means of actions that allow the emergence of biased immobilism, reconstructing pedagogical practices that express the richness of identities through cultural dialogue rethought with the possibilities of diversity and plurality.

KEYWORDS: Otherness. Education. Sexual diversity.

\section{Introdução}

Embora Emmanuel Lévinas (1980) não trate diretamente da questão da sexualidade na escola, o autor deixa entrever no seu discurso o panorama social em que se justifica a preocupação com o outro da relação formativa, que passa pela alteridade e pelo respeito às diferenças. Para Gadamer (2000), podemos dizer que o ser que pode ser compreendido é linguagem e desfruta da interação (que o emancipa) com o outro. Para tanto, o "eu” só poderá existir em contato e mediação com o "outro", em uma relação de diálogo e reconhecimento das diferenças existentes. Daí que o debate sobre a alteridade é uma demanda contemporânea, pois envolve uma relação de reciprocidade e abertura às diferenças, ao outro, que é mais fraco e tem precedência na relação intersubjetiva. $\mathrm{O}$ encontro com o outro na escola é uma relação político-social, não somente pelo fato de ser um contato de sujeitos do mesmo gênero ou uma união de semelhantes, mas pela exigência recíproca de compartilhar conhecimentos e de responsabilizar-se pelo outro. Ao entrar em contato com o outro que é diferente,

[...] ninguém pretende mudar para assumir a identidade oferecida pelo outro, mas a aceitação da diversidade com base na alteridade permite um novo pacto, uma nova negociação em que cada um reconhece a identidade do outro, mas conjuntamente, complementarmente, tratando-se em condições de pares. (PIERONI; FERMINO; CALIMAN, 2014, p. 29).

Neste viés, há um grande poder intelectual e social da educação que contribui para uma relação de "conviver" (viver junto) com o outro, no respeito à singularidade de cada ser. Em contraposição, vivemos um momento difícil, que nos traz a seguinte problematização: de que forma podemos mobilizar a cultura do diálogo com as diferenças e a diversidade sexual na educação, contribuindo para resistir aos estereótipos e distorções sociais que inviabilizam o reconhecimento do outro? 
Esse esforço interpretativo da realidade tem por finalidade compreender o que a educação pode oferecer para repensar o diálogo intersubjetivo ${ }^{4}$, a fim de compreender, desmistificar e reconhecer a diversidade sexual para que todos sejam respeitados na sua integridade física, de valor e de caráter. Busca-se, assim, em Lévinas, o conjunto de categorias que coloca a alteridade como princípio articulador e compreensivo do saber das diferenças, promovendo uma reflexão crítica sobre os abismos que há na convivência com a diversidade. Esse processo de leitura da realidade acontece por meio da hermenêutica, pelo desafio do conversar com o outro, que se propõe a encontrar o sentido e o significado dos fatos em sua historicidade. Trata-se não apenas de compreender os processos que levaram ao não reconhecimento e expulsão dos diálogos sobre a diversidade sexual nas instituições de ensino, mas principalmente de construir novas perspectivas, que superem o vazio do pensar sensível, afetivo e descentrado culturalmente. Afinal de contas, compreender é um ato infindável de reconciliação com o outro (a partir de sua originalidade e não de convenções sociais), com a linguagem, com a natureza, com a realidade e com o mundo.

Pensamos em uma educação que não pode ser dissociada da esfera da alteridade, do trabalho com o pensar coletivo, que reconhece a multiculturalidade e a diversidade. Isso porque toda ação pedagógica é um ato político. Trata-se de um fenômeno de alteridade, uma vez que o educando cresce e se desenvolve na relação com o outro e no pensar sobre como deve agir na deliberação de suas próprias ações. Olhar para o outro na educação assume lugar de importância basilar para o processo de construção do conhecimento, uma vez que dar voz ao outro significa aprender com ele, contribuindo à formação e transformação humana.

A pesquisa aponta as dificuldades e as resistências educacionais diante de horizontes fragmentados, rígidos e castradores de uma expectativa de abertura às diferenças, construindo uma cultura do diálogo, respeito, responsabilidade, bondade, reciprocidade, honestidade e compromisso com o outro. A partir de Lévinas, justificamos a alteridade nos processos educativos e a sua importância em relação à diversidade sexual no cotidiano escolar, no currículo e nas práticas interdisciplinares, a fim de vivificar relações humanizadas ${ }^{5}$. Isso é

4 A experiência intersubjetiva encontra-se no centro da compreensão contemporânea dos processos de constituição de subjetividade, configurando uma ética de imprescindibilidade do outro para a produção do si mesmo, na qual o outro aparece como irredutível, na sua alteridade absoluta. Nas leituras de Lévinas (1993; 2005) sobre a intersubjetividade, o outro não é compreendido como um outro eu (como nos discursos tradicionais de amizade), mas como absolutamente outro, que me questiona, destroçando a soberania do eu; a subjetividade humana surge, constitui-se, no encontro ético de acolhimento do outro (como rosto, na sua absoluta estranheza). Nesse sentido, a alteridade é constitutiva da subjetividade e engloba a sociabilidade na relação face a face, pois me obriga e exige de mim uma resposta.

${ }^{5} \mathrm{O}$ ser humano pode ser caracterizado como um diálogo da phisis (natureza) com o logos (razão viva). Daí que toda a problematização da linguagem pressupõe que esta já nos tenha falado. A linguagem é um dirigir-se a nós e ao outro, sem o qual não poderemos falar. 
possível, uma vez que "a prática da alteridade como Desejo do Outro nunca é saciada, porque, quanto mais o sujeito se abre ao outro, tanto mais ele se abre à prontidão ilimitada de acolher" (REIMER, 2011, p. 184). O outro como alteridade ensina e o eu que aprende.

Adota-se como fio condutor para a análise a abordagem hermenêutica, que é voltada para a compreensão e a interpretação de discursos, textos e todas as formas de criação humana, que almeja a apropriação de sentido de uma temática silenciada e que precisa ser despertada na escola. Como escuta da linguagem do outro, a hermenêutica é a própria fusão de horizontes onde as tradições culturais e interpretativas acontecem e se escutam mutuamente, propondo-se, justamente, deixar que o outro seja outro, satisfazendo a exigência que move a alteridade. A retomada da humanização das relações interpessoais pode acontecer pelo caminho da conversação hermenêutica, que nos constitui no encontro com o diferente. Nesse contexto, a linguagem torna-se base para a construção do conhecimento, uma vez que os debates educativos necessitam de uma atitude hermenêutica, já que exige um trabalho interpretativo que parte dos contextos culturais da realidade emergente. A atitude hermenêutica é uma perspectiva dialógica que garante a interpretação e a compreensão de diferentes visões de mundo como questões fundamentais e motivacionais para avançar no diálogo com as diferenças. Ao propor a intersubjetividade como base deste estudo, as contribuições de Lévinas são provocadoras para um novo olhar, tecendo metáforas e analogias frente às questões da sexualidade na escola. A alteridade passa a ser reconhecida como premissa imprescindível para o ambiente escolar, uma vez que,

[...] sendo a escola parte integrante e contextualizada da sociedade, observamos que diferentes manifestações de preconceito, discriminação, diversas formas de violência - física, simbólica, bullying -, homofobia, intolerância religiosa, estereótipos de gênero, exclusão de pessoas deficientes, entre outras, estão presentes em nossa sociedade, assim como no cotidiano das escolas. (PIERONI; FERMINO; CALIMAN, 2014, p. 23).

A partir deste estudo visamos somar esforços no sentido de tornar visível e criar estímulos para uma ação pedagógica atenta às diferenças culturais e sociais que nos constituem, bem como aos saberes históricos que precisam ser reconstruídos pela cultura do diálogo na escola. Definir a alteridade no cenário educativo significa valorizar as diferenças e a conversação de abertura ao outro, para promover relações mais humanas e justas, levando em consideração as manifestações de identidades sexuais, presentes no mundo de relações sociais híbridas e de configurações diversas. 


\section{Inter-relações da Alteridade em Lévinas e a diversidade sexual}

Tendo por base as experiências vivenciadas na Segunda Guerra Mundial, Emmanuel Lévinas (1906-1995) $)^{6}$ construiu seu pensamento filosófico, tendo como ponto de partida a concepção da ética do outro. "O autor procura descobrir como a ética, enquanto relação concreta com o rosto do outro, pode produzir-se como razão", opondo-se à razão solipsista ${ }^{7}$ e individualista, que inviabiliza ou marginaliza as diferenças humanas (KUIAVA, 2014, p. 328). O trabalho de Lévinas se traduz no respeito pelo outro, em um desejo incondicional que é ilustrado na seguinte analogia: "a constatação a que chegou Descartes, expressa na declaração ontológica 'penso, logo existo', em Lévinas poderia ganhar um acréscimo muito importante, o outro, fica assim reconstruída: 'Penso no 'outro', logo existo” (REIMER, 2011, p. 184). Com Lévinas percebemos que é imprescindível uma mudança de postura frente aos acontecimentos que a história nos revela, pois diante de episódios históricos marcados por ações bárbaras e desumanas, Lévinas centra a importância no reconhecimento ético do humano e no respeito às diferenças como a possibilidade de superar a indiferença, no sentido de encorajar e aprender com os outros na experiência de solidariedade e de estima social. Por meio do reconhecimento do outro, somos convidados a entender que a identidade pessoal é resultado da estrutura intersubjetiva de uma sociedade plural e nem sempre fraterna. Precisamos lembrar que o próprio Lévinas perdeu a maioria de seus familiares no período nazista. Neste contexto, um sujeito que perde a sensibilidade, a humanização, acaba por perder o princípio da alteridade, de olhar e se identificar com o outro.

Lévinas realiza uma leitura que escapa dos preceitos ontológicos e idealísticos disseminados na modernidade, em que nada existe fora do pensamento individual e apresenta uma ética fundada no pluralismo, em que todos são unidos pela paz, de uma subjetividade descentrada. É por isso que "a racionalidade não é mais cálculo, nem um universo controlado por regras e procedimentos, [posto que] a sabedoria passa a não ser mais pensada em termos

\footnotetext{
${ }^{6}$ Emmanuel Lévinas, judeu, natural da Lituânia, viveu entre os anos de 1906 e 1995. Com a Primeira Guerra Mundial (1914), sua família refugiou-se na Ucrânia, retornando à Lituânia em 1920. Em 1923, emigrou para a França, onde estudou latim e filosofia. Em 1928, mudou-se para a Alemanha e continuou seus estudos com Husserl, por meio de quem conheceu Heidegger, aos 22 anos. Aos 34 anos (1940) foi preso e levado para um campo de concentração em Hannover, saindo somente com o fim da guerra, em 1945. De volta à França, reencontrou sua esposa, que se refugiara em um convento vicentino e construiu uma densa reflexão filosófica justificada na grandeza do outro que sustenta a relação. Sobre o tema consultar: GUEDES. Edson Carvalho. Alteridade e diálogo: uma meta-arqueologia na educação a partir de Emmanuel Lévinas e Paulo Freire. Tese (Doutorado em Educação). Universidade Federal da Paraíba, João Pessoa, 2007. Disponível em: <http://tede.biblioteca.ufpb.br/bitstream/tede/4826/1/arquivototal.pdf > Acesso em: 29 mar. 2016.

7 O problema central da filosofia ocidental sempre esteve voltado para a discussão da relação solitária "consciência-mundo", colocando em segundo plano a questão da alteridade, como um motivo para a real convivência com outros seres humanos (KUIAVA, 2014, p. 324).
} 
de conhecimento". (KUIAVA, 2014, p. 335; p. 324). Em outras palavras, "a filosofia de Lévinas consiste em afirmar que na relação com outrem, com o rosto, o infinito vem à ideia, como um despertar da consciência, como condição necessária para que haja um saber”. (KUIAVA, 2014, p. 330). Assim, a manifestação do rosto do outro, em uma dimensão maior, fala por si só, tornando-se a procedência de todo o sentido social e culturalmente construído. Em seu pensamento, a expressão humana se forma na palavra que movimenta o outro e dialoga com a nossa própria formação em obra, em processo de inacabado de reinvenção.

O acontecimento próprio da expressão consiste em dar testemunho de si, garantindo esse testemunho. Essa atestação de si só é possível como rosto, isto é, como palavra. Ela produz o começo da inteligibilidade, a própria inicialidade, o principado, a soberania real, que comanda incondicionalmente. (LÉVINAS, 1980, p. 180).

Ao trazer estas ideias para os dias de hoje, buscamos debater no cenário educativo que é, ou deveria ser, marcado pela palavra de abertura ética ao outro, que traz sua própria autenticidade cultural, valores experienciais e sociais, por vezes, contraditórios. Isso nos impulsiona a pensar na contemporaneidade, na importância da alteridade à construção de uma sociedade emancipadora e libertadora. Para Freire (1998), a educação, ao invés de satisfazer o eu numa espécie de sentimento individualista, tem sentido quando alcança o sentimento solidário e coletivo, que alonga a mão ao outro, superando a opressão pelo reconhecimento e estímulo à curiosidade epistemológica do outro.

Os atos de reconhecer e ser reconhecido são eminentemente humanos, por isso possuem caráter político e pedagógico, constituindo nossa condição de manifestação humana, de criação e reconstrução de conhecimentos. Ao inserirmos a compaixão, a empatia e a dignidade humana como princípios da arte de educar, nos damos conta de que a exclusão dos outros significa a redução da capacidade de apreender de nós mesmos. A ideia da segregação dos sujeitos pode ser analisada na instância da evasão escolar, por exemplo, uma espécie de marginalização e exclusão dos outros de forma institucionalizada, dependente da nossa própria vontade (um "eufemismo cruel" diria Freire). Ou seja, a exclusão social e cultural apresenta-se através de muitas facetas, revelando-se no desrespeito à condição peculiar de desenvolvimento humano, reprimindo a autenticidade, a criatividade, a cultura do diálogo e a autonomia do outro pelas ações que realizamos (talvez ameaçadoras, opressoras, desmotivadoras e autoritárias), inclusive por meio de ditaduras de gênero na escola.

Como já mencionado, Lévinas (1980) amplia o conhecimento intersubjetivo, colocando a relação com o outro antes de qualquer conhecimento racional e conceitual, 
implicando, antes de tudo, responsabilidade e respeito. $\mathrm{O}$ encontro com o outro é precedente a toda e qualquer teoria, pois é neste encontro que surge um novo conceito, conhecimento e episteme. A prática da alteridade serve para a promoção da justiça social e respeito das desigualdades, uma vez que "o amor é o eu satisfeito pelo tu, captando em outrem a justificação de seu ser. [...] O calor afetivo do amor realiza a consciência dessa satisfação, desse contentamento, dessa plenitude, encontrados fora de si, excêntricos”. (LÉVINAS, 2005, p. 147). Nessa perspectiva, a responsabilidade é o que dá sentido e caracteriza a abertura diante do outro, sem dissimulações, sem a negação do outro para garantir o respeito de sua dignidade e globalidade. Nessa dinâmica, a relação com o outro sensibiliza para diferentes instâncias da formação mobilizada socialmente, que evidencia conflitos e luta por reconhecimento de si em direção ao outro. "A relação com o Outro questiona-me, esvazia-me de mim mesmo e não cessa de esvaziar-me, descobrindo-me possibilidades sempre novas. Não me sabia tão rico, mas não tenho mais o direito de guardar coisa alguma". (LÉVINAS, 1993, p. 56).

É preciso olhar para o rosto do outro, dado que "o discurso condiciona o pensamento, porque o primeiro inteligível não é o conceito, mas uma inteligência, cuja exterioridade inviolável o rosto enuncia”. (LÉVINAS, 1980, p. 194). O princípio passa a ser de justiça, de paz, uma vez que "justificar a liberdade não é demonstrá-la, mas torná-la justa”. (LÉVINAS, 1980, p. 70). Por isso, investir em educação significa valorizar e reconhecer o outro que não faz parte de mim, mas é aquele que dá sentido para a minha existência. O outro não é a uniformidade em pessoa ou um objeto a meu serviço, mas um sujeito de valor com outras experiências e saberes, de relações complexas e dinâmicas com o universo social. É nesse sentido que a ética da alteridade nos impele a sermos responsáveis pelo desenvolvimento do outro, que nos interpela e que talvez deixou de ser reconhecido pela indiferença às diferenças (sexuais, de origem social, religiosa, étnica, em sentimentos, argumentos, projetos, vontades, habilidades, desejos, gostos, etc.). Uma ética da alteridade é encarada por nós como um desafio necessário para revitalizar o diálogo de abertura para o saber do outro que nos emancipa, pois nos permite aprender sempre. Precisamos caminhar para uma sociedade que preze e valorize a existência do outro e que não busque a uniformização do ser, ou até mesmo, a desvalorização do outro, em uma relação de império e dominação do eu frente ao alter.

\section{Alteridade e a Diversidade Sexual: repercussões sensíveis à educação}


Compreende-se que a educação tem um importante papel de formação cultural, muitas vezes sabotado e aniquilado nos espaços educativos em nome de um ensino homogeneizador, hierarquizado, dicotômico e abstraído do contexto vital, causando insensibilização e frieza diante das diferenças e do sentido do humano. Essa característica precisa ser revisada, especialmente para romper com os tabus sociais, como é o caso das desigualdades de gênero historicamente perpetuadas. A sexualidade está presente na escola, pois é um espaço de interação e de convívio social, onde as pessoas se mostram, se re-conhecem e porque, obviamente, é um espaço para a construção de identidades (como manter uma identidade se o homem é mutação?), de renovação da tradição cultural e de aprendizagens sociais.

Mas como abordar este tema paradoxal, enigmático e ambíguo, ligado aos gêneros e sexualidades, que ainda é conflituoso e desafiador nas práticas pedagógicas e curriculares? Para ilustrar, a escola tem grande compromisso quando um jovem com um problema sexual ou que sofre por conflitos relacionados à orientação sexual não é respeitado em sua diferença em sala de aula. Se a escola não olha e debate sobre essas questões, ignorando projetos voltados ao reconhecimento do outro e à convivência inclusiva, recairá na perpetuação de preconceitos sociais, na interdição e no silenciamento do outro. Mesmo porque,

[...] a inscrição dos gêneros, feminino ou masculino, nos corpos é feita, sempre, no contexto de uma determinada cultura e, portanto, com as marcas dessa cultura. As possibilidades da sexualidade, das formas de expressar os desejos e prazeres, também são sempre socialmente estabelecidas e codificadas. As identidades de gênero e sexuais são, portanto, compostas e definidas por relações sociais, elas são moldadas pelas redes de poder de uma sociedade. (LOURO, 2001, p. 11).

As escolas têm várias expressões de violência, desde agressões verbais e físicas, brincadeiras agressivas, humilhações, ameaças, indisciplina excessiva, desrespeito, que são violências que surgem das condições sociais de produção do discurso e visam à homogeneização dos corpos e das formas de pensar. A educação sensível a todas as dimensões humanas (objetivas, sociais e subjetivas) conecta a linguagem pedagógica à própria construção identitária dos sujeitos, inclusive a dimensão da sexualidade.

Historicamente, a educação carregada uma distinção binária de ser masculino e feminino, sempre indicando uma expectativa idealizada e evidenciando uma visão pejorativa e distanciada do que é diferente. Daí que as questões sobre gênero não podem ser uma repetição simplesmente da tradição cultural (frequentemente preconceituosa em relação ao que difere do convencional e inquestionada), mas, na educação seria a decisão de fazer algo 
que necessita do vínculo dialógico com o outro. Já é de consenso que toda identidade sexual é um construção histórico-cultural permeada por relações sociais contraditórias.

[...] é fundamental ter a consciência de que a educação sexual é tarefa da escola, os fatos acontecem na escola, em segundo plano é imprescindível à formação continuada, prolongada e com assessoria para a prática pedagógica, pois muitos educadores não tiveram contato com a temática na sua formação[...]. O reconhecimento da complexidade que envolve a temática abordada neste trabalho aponta para a real necessidade de a escola instrumentalizar-se para fornecer informações mais precisas para questões que são respondidas indevidamente. A educação é, ou deve ser instrumento dessa ação, na medida em que possibilita ao homem tomar consciência da realidade em que vive e, em consequência, agir para transformar essa realidade. (ARGENTI; MILANI, 2017, p. 220-221).

$\mathrm{Na}$ concretude da vida educativa, todo conceito que não é contextualizado torna-se alienante e alienado. $\mathrm{O}$ ser humano constitui-se em processos que acontecem por intermédio da cultura, e a constituição da diversidade de gênero ocorre de forma dinâmica e processual, algo que aprendemos nas diferentes formas de vida (por meio do exercício da linguagem, da abertura à diferença de rupturas). Porém, é patente que os mais diferentes estabelecimentos de poder ideológico (mídia, igreja, família, escola) ainda impõem um modelo ideal e não contemplam a cultura do diálogo. Esse caminho de policiamento em relação à sexualidade na escola levou ao nascimento de vozes que clamam pelas diversas formas de gênero e de orientação sexual. O grande desafio, nesse campo, está no amadurecimento intelectual para a compreensão da multiplicidade, sem recair em extremismos, representando a exclusão pela sexualidade, ou em esquemas binários de homem-mulher, generalização apressada ou neutralização das diferenças. Por tudo isso, o nosso olhar está voltado para a alteridade, no sentido de aceitar e dialogar sobre as diferenças na escola como uma forma de abordar os conhecimentos indizíveis e criar um entendimento mais democrático, aproximativo e de interação cultural. Conforme Louro (2001, p. 21),

Na escola, pela afirmação ou pelo silenciamento, nos espaços reconhecidos e públicos ou nos cantos escondidos e privados, é exercida uma pedagogia da sexualidade. Legitimando determinadas identidades e práticas sexuais, reprimindo e marginalizando outras. Muitas outras instâncias sociais, como a mídia, a igreja, a justiça, etc., também praticam tal pedagogia, seja coincidindo na legitimação e denegação de sujeitos, seja produzindo discursos dissonantes e contraditórios.

Certamente, tudo o que vai mudando causa novas aprendizagens, por isso a necessidade de desacomodar estereótipos fixados culturalmente, como é a questão de gênero e sexualidade. Comportamentos como chacotas, presentes no ambiente escolar, ocorrem na 
tentativa de estabelecer a normatização da conduta, a homogeneização e a linearidade da formação cultural. A heteronormatividade surge enquanto conjunto de regras sociais que normalizam as identidades de gênero, estabelecendo maneiras de ser nas atitudes e comportamentos.

A educação, nesse viés, tornar-se uma esfera de potencial emancipador voltado para o desenvolvimento de uma ética da alteridade planetária (LÉVINAS, 1980). Ela tem por base referencial a promoção do diálogo das culturas e da responsabilidade com o outro na experiência educativa, para o desenvolvimento de uma cultura do diálogo. Mas é notório o quanto distante encontra-se esse ideal educativo na prática, já que a educação nem sempre desenvolve uma dimensão de responsabilidade do eu para com o outro. Realizar experiências educacionais como um lugar de encontro com o outro se constitui de forma contrária a uma relação que coisifica e rotula o outro, estando disponível para projetar-se para novas perspectivas desconhecidas, sendo capaz de se expor para o imprevisto, com os riscos, a insegurança e a inquietude que o encontro oportuniza. Pelo reconhecimento do valor das diversas culturas e modos de vida como base da experiência do encontro com o outro, aquele que não se aventura para o desconhecido não é capaz de perceber as transformações intersubjetivas no encontro com a própria realidade social e com os conhecimentos que pode apreender. Dessa forma, sendo a escola um lugar de encontro com o outro e de abertura à diversidade, é visível a necessidade do estabelecimento de relações dialógicas entre as diferentes disciplinas, tendo em vista a promoção de uma ética da alteridade, solicitude e escuta, enfim, um lugar sensível à cultura das diferenças. A diversidade pode ser entendida como um processo humano subjacente à construção histórica e cultural de todo o processo educativo, que converge no sentido da:

Educação para a alteridade: caracterizar a relação de troca em base à complementariedade, ao duplo discurso, à introdução da interação na prática educativa, da troca, da reciprocidade, partindo do princípio segundo o qual o encontro com a diversidade gerará a ideia de heterogeneidade; aceitando-a, poderemos descrevê-la, poderemos falar sobre ela, construir sua lógica interna. Nesse sentido, parece obsoleto falar de assimilação, de integração e de inserção social. Cada identidade requer a aceitação de sua realidade: de afro, de gay, de mulher, de ancião, de cigano, de menino de rua... (PIERONI; FERMINO; CALIMAN, 2014, p. 23).

Em geral, a formação de uma cultura da alteridade, mais respeitosa e sem preconceitos, é um processo coletivo, pois a aprendizagem se faz através de relacionamentos e atos entre sujeitos na vida em sociedade. 
Aceitar e respeitar a diferença é uma dessas virtudes sem o que a escuta não se pode dar. Se discrimino o menino ou menina pobre, a menina ou menino negro, o menino índio, a menina rica; se discrimino a mulher, a camponesa, a operária, não posso evidentemente escutá-las e se não as escuto, não posso falar com eles, mas a eles, de cima para baixo. Sobretudo, me proíbo entendê-los. Se me sinto superior ao diferente, não importa quem seja, recuso-me escutá-lo ou escutá-la. O diferente não é o outro a merecer respeito é um isto ou aquilo, destratável ou desprezível. (FREIRE, 1998, p. 136).

Retomando a importância da escuta e da palavra, vivencia-se no meio educacional um processo mais ético em relação ao outro, para além de um desconforto diante de uma atitude estranha ou do impensado (por exemplo, as invenções de Leonardo Da Vinci). É através do desenvolvimento de visões de mundo em interação dialógica que se revelam os vínculos éticos de abertura ao outro. Importante notar que ao me dirigir ao outro, independentemente de seu gênero ou orientação sexual, jamais deixaremos de ser, sentir e agir humanos, em outras palavras, de sermos nós mesmos.

A partir das projeções da alteridade apresentada por Emmanuel Lévinas (2005), passamos a ser responsabilizados pelo outro (o qual não podemos narrativamente rechaçar) e impelidos a um diálogo aberto culturalmente entre todas as áreas de conhecimento, em coparticipação, pois o exercício de alteridade implica uma postura ativa para desenvolver aprendizagens evolutivas. A alteridade intersubjetiva jamais poderá ser substituída ou recusada, é uma potencialidade inviolável da transformação humana. A partir da compreensão de que no rosto do outro está projetada a liberdade, o respeito, a singularidade faz com que eu respeite integralmente a subjetividade alheia. Afinal de contas, jamais posso violar ou sobrepor minha subjetividade se entendo que "a alteridade está como que inscrita na própria estrutura da subjetividade, ou seja, como transcendência que se converte em um movimento em direção ao outro" (KUIAVA, 2014, p. 326). Transcender (algo presente nos atos mais naturais e comuns da existência) é manter uma abertura ao outro de forma sensível e integral, sem a rigidez da oposição, sem recair em uma visão ingênua que desconsidera a historicidade, as conexões históricas ou queira mudar a subjetividade. Nesse contexto,

A palavra do outro é mandamento que interpela o primado da justiça frente à razão e à liberdade. Esse é o motivo pelo qual Lévinas põe em questão a liberdade. O mau uso da liberdade, como, por exemplo, o egoísmo, pode até conduzir a uma tentação de querer reduzir o outro ao mesmo, à categoria de objetividade, tentando inclusive assassiná-lo. Mas, o outro, na sua manifestação, questiona a espontaneidade, é o infinito que o eu não pode dominar, nem teoricamente, nem pelo poder da vontade. (KUIAVA, 2014, p. 334). 
Para Lévinas (1980, p. 190), reconhecer o outro é "o primeiro gesto ético" de responsabilidade pelo outro e de racionalidade ética do dizer e da capacidade de escutar, que brota da subjetividade e que aponta para uma outra dimensão de si mesmo. O ser humano ao reconhecer o outro se abre para o aprender e o falar com o mundo e não fica mais indiferente às situações emergentes, pois, "os diretos do outro não podem ficar à mercê do eu e da sua boa vontade" (KUIAVA, 2014, p. 328).

Para a construção do saber intersubjetivo que possibilita uma vida digna para todos, na construção de paz, liberdade de expressão e justiça social, o relatório da UNESCO (1998), coordenado por Jacques Delors, tem sido um dos textos fundamentais no desenvolvimento da educação - pensada como uma das artes para superação de crises contemporâneas. Assentado em quatro pilares, a ênfase ${ }^{8}$ foi dada ao aprender a viver juntos, aprender com os outros, desenvolvendo o conhecimento em contato com os outros. O documento afirma que: "sem dúvida, esta aprendizagem representa, hoje em dia, um dos maiores desafios da educação. O mundo atual é, muitas vezes, um mundo de violência que se opõe à esperança posta por alguns no progresso da humanidade.” (DELORS, 1998, p. 96). Este relatório está em consonância com Lévinas, uma vez que diante do outro (que me afeta) precisamos aprender a viver juntos ou vamos padecer como idiotas. Paradoxalmente, para se abrir ao saber que brota do outro e que produz obras concretas pela sabedoria do amor (que comporta elementos de responsabilidade, boa vontade e sair de si - descentrar-se), é necessário ser para o outro, como “uma possibilidade para uma relação de alteridade" (KUIAVA, 2014, p. 335).

A educação passa a ser entendida como um conjunto de processos formativos que se desenvolvem em diversas dimensões e sua característica principal é a de ser uma arte intersubjetiva, atravessada por relações de ensino e de aprendizagem, em que o diálogo encontra a alteridade. Ao pensar no outro, a escola não pode permanecer surda ao apelo do educando, dominá-lo ou esquecê-lo, "sem que eu possa cessar de ser responsável por sua miséria" (LÉVINAS, 1993, p. 60). A educação coloca o educando diante do conhecimento, da interpretação social e do mundo intersubjetivo, para o exercício da cidadania e para relações recíprocas, reconhecendo e dando voz às diversidades como atitude generosa, engajada e encorajadora em relação ao desejo de saber, ao compreender e ao aprender com o outro.

8 Os demais três pilares 'aprender a conhecer', que diz respeito às habilidades para a aquisição dos conhecimentos; 'aprender a fazer', um conhecimento que faz do ser humano um eterno aprendiz; e, por último, 'aprender a ser', que visa a "realização completa do homem, em toda a sua riqueza e na complexidade das suas expressões e dos seus compromissos", enquanto "indivíduo, membro duma família, duma coletividade, cidadão e produtor, inventor de técnicas e criador de sonhos". (DELORS, 1998, p. 101). São quatro aprendizagens interdependentes, que estabelecem múltiplos pontos de contato neste mundo complexo em suas diversidades, cabendo à educação contribuir para compreender melhor o outro e construir uma vida de mais reciprocidade para o saber (re)conhecer.

Doxa: Rev. Bras. Psico. e Educ., Araraquara, v. 20, n. 1, p. 65-79, jan./jun., 2018. e-ISSN: 2594-8385. 


\section{Considerações finais}

Concluímos que entrar em diálogo com o outro, a partir de Lévinas, traz novas possibilidades e capacidades de abrir novos horizontes sobre as questões de sexualidade na escola, obrigando a novas revisões, modificações e aprofundamentos, como possibilidade de pôr-se em relação com a alteridade, com o mundo e com a criação da mediação das relações educativas. Como dissemos, só reconhecendo os problemas da educação podemos construir a nossa história onde estamos inseridos no enfrentamento à reprodução de preconceitos e ideologias totalitárias, para transformar experiências enunciadas e aprender com as diferentes formas de vida, tomando como referência as diferentes versões como oportunidade de florescer as diferenças, as lutas e os paradoxos que nos constituem. Sem a possibilidade de dialogar sobre as representações sociais do masculino e feminino, acabamos reforçando a resolução normatizadora dos corpos pedagogicamente moldados pela direção biológica e ocupando certos papéis sociais, inferiorizando e naturalizando comportamentos. A perpetuação de papéis de gênero envolve atos de controle de relações nem sempre justas, que marcam condutas de ação, alimentando divisões desiguais e estabelecidas em nossa cultura e educação, em modelos de sexualidade, masculinidade e feminilidade (LOURO, 2001).

Esta construção traz à luz elementos como a exposição das crianças e jovens a situações que apresentam somente os modelos de feminilidade e masculinidade, cerceando a liberdade de escolha e o desenvolvimento comportamental, como por exemplo, em situações de brincadeira, em escolhas de brinquedos, cores, etc. Nesse sentido, o ambiente escolar tem sido, e isto desde a educação infantil, um espaço onde a sexualidade é reprimida de forma vigiadora e normatizada em que acaba desenvolvendo determinadas representações “adequadas" para meninas e meninos, de acordo com o padrão apresentado pela sociedade. Assim, nega-se uma educação sensível às diferenças e à alteridade e apresenta-se uma face injusta e obscura que violenta a existência de outras formas de diversidade esquecidas, impossibilitando a escuta, fechando definitivamente a porta ao diálogo, uma vez que as identidades são teleguiadas e imobilizadas pela neutralização e fixação de representações. A relevância da alteridade na educação depende de uma relação estabelecida no falar e ver o outro como abertura para o (re)conhecer a si mesmo pelo diálogo com o outro e com os diferentes mundos e experiências. Talvez um modo de manter vivo o diálogo seja perguntar por que permanecer no reducionismo e resistência à diversidade e multiplicidade na educação ao invés de deixar que o outro seja outro? A reflexão pode constituir-se na experiência de 
abertura ao outro e à própria realidade enquanto diálogo pungente, para aprender evolutivamente com o diverso.

\section{REFERÊNCIAS}

ARGENTI, Paula Camila.; MILANI, Débora Raquel da Costa. Educação sexual e docência: as relações de gênero, a diversidade e a sexualidade dentro da escola. Doxa: Rev. Bras. Psicol. Educ., Araraquara, v. 19, n. 2, p. 212-223, jul./dez. 2017.

DELORS, Jacques. Educação, um tesouro a descobrir: relatório para a UNESCO da Comissão Internacional sobre Educação para o século XXI. Porto, Portugal: UNESCO, Edições Asa, 1998.

FREIRE, Paulo. Pedagogia da autonomia: saberes necessários à prática educativa. Rio de Janeiro: Paz e Terra, 1998.

GADAMER, Hans-Georg. Da palavra ao conceito: a tarefa da hermenêutica enquanto filosofia. In: ALMEIDA, Custódio Luís Silva de.; FLICKINGER, Hans-Georg.; ROHDEN, Luiz (orgs.). Hermenêutica filosófica: nas trilhas de Hans-Georg Gadamer. Porto Alegre: EDIPUCRS, 2000.

KUIAVA, Evaldo. Ética da Alteridade. In: TORRES, Carlos Brum João (Org). Manual de ética: questões de ótica teórica e aplicada. Petrópolis, RJ: Vozes; Caxias do Sul, RS: Universidade de Caxias do Sul; Rio de Janeiro: BNDES, 2014. p. 324-345.

LÉVINAS, Emmanuel. Totalidade e infinito. Trad. José Pinto Ribeiro. Lisboa: Edições 70, 1980.

LÉVINAS, Emmanuel. Humanismo do outro homem. Trad. Pergentino S. Pivatto. Petrópolis: Vozes, 1993.

LÉVINAS, Emmanuel. Entre nós: ensaios sobre a alteridade. 2. ed. Petrópolis: Vozes, 2005.

LOURO, Guaciara Lopes (org.). O corpo educado: pedagogia da sexualidade. Belo Horizonte: Autêntica: 2001.

PIERONI, Vittorio.; FERMINO, Antonia.; CALIMAN, Geraldo. Pedagogia da alteridade. Para viajar a Cosmópolis. Brasília: Líber Livro, 2014.

REIMER, Richter Ivoni. Direitos Humanos: enfoques bíblicos, teológicos e filosóficos. São Leopoldo: Oikos, Goiânia: PUC, 2011. 


\section{Como referenciar este artigo}

HABOWSKI, Adilson Cristiano.; CONTE, Elaine.; JACOBI, Daniel Felipe. Alteridade e educação: um diálogo intersubjetivo pelo viés da diversidade. Doxa: Rev. Bras. Psico. e Educ., Araraquara, v. 20, n. 1, p. 65-79, jan./jun., 2018. e-ISSN: 2594-8385. DOI: 10.30715/rbpe.v20.n1.2018.11273

Submetido em: 06/04/2018

Aprovado em: 18/05/2018 